\title{
Investigation of Some Heavy Metal Levels in Drinking Waters in Bingol Region
}

\author{
Semih Yasar (Corresponding Author) \\ Department of Medical Laboratory Techniques, Vocational High School of Ozalp, \\ Van Yuzuncu Yil University, Ozalp, Van, Turkey \\ E-mail: semihyasar@yyu.edu.tr \\ Aykut Cagirtekin \\ Private Tarsus Cukurova College, Tarsus- Mersin, Turkey \\ E-mail: 2306kimya@mynet.com \\ Leyla Mis \\ Department of Physiology, Faculty of Veterinary Medicine, \\ Van Yuzuncu Yil University, Tusba, Van, Turkey \\ E-mail: leylamis@yyu.edu.tr \\ Tuncer Cakmak \\ Republic of Turkey Ministry of Agriculture and Forestry, Van Provincial Directorate of \\ Agriculture and Forestry, Department of Food and Feed Branch Office, Van, Turkey \\ E-mail: tuncercakmak65@hotmail.com
}

\begin{abstract}
In this study, drinking water throughout the province of Bingol in eastern Turkey has been established in 2013 for the determination of copper $(\mathrm{Cu})$, manganese $(\mathrm{Mn})$, cobalt $(\mathrm{Co})$ and iron $(\mathrm{Fe})$ concentrations of the Turkish Standards Institute (TSE) as humanitarian drinking water standards. For the study, a total of 13 samples were taken from the drinking water sources located in Bingöl province, previously washed with $1 \% \mathrm{HNO} 3$ solution, using $1.5 \mathrm{~L}$ volume pet bottles with locked lid. Water samples were analyzed with the AAS device. According to the results of the analysis; $\mathrm{Cu}$ and $\mathrm{Fe}$ concentrations were found to be high and $\mathrm{Mn}$ and $\mathrm{Co}$ concentrations were high. In the regions where $\mathrm{Mn}$ and $\mathrm{Fe}$ concentrations are high, taking the necessary precautions regularly is important for public health.
\end{abstract}

Key Words: Bingol, Heavy metal, Water.

DOI: $10.7176 / \mathrm{JSTR} / 5-2-32$

\section{Bingöl Bölgesi İçme Sularında Bazı Ağır Metal Düzeylerinin Araştırılması}

Özet

Bu çalışmada Türkiye'nin doğusunda bulunan Bingöl ili genelinde bulunan içme sularında Bakır $(\mathrm{Cu})$, Mangan (Mn), Kobalt (Co) ve Demir ( $\mathrm{Fe}$ ) konsantrasyonlarının Türk Standartları Enstitüsü (TSE)'nün insani amaçlı içme ve kullanma suyu standartlarına uygun olup olmadığının tespiti için 2013 yılında yapılmıştır. Çalışma için Bingöl il genelinde bulunan içme suyu kaynaklarından olmak üzere daha önceden \%1'lik $\mathrm{HNO}_{3}$ çözeltisiyle yıkanmış, kilitli kapaklı, 1,5L hacmine sahip pet şş̧eler kullanılarak toplam 13 numune alınmıştır. Alınan numuneler içerisine 15'er $\mathrm{ml} \% 65$ lik $\mathrm{HNO}_{3}$ çözeltisi eklenerek 
numuneler analiz gününe kadar $-18^{\circ} \mathrm{C}$ de muhafaza edilmiştir. Su numunelerinin analizleri AAS cihazı ile yapılmıştır. Analiz sonuçlarına göre; $\mathrm{Cu}$ ve Fe konsantrasyonlarının standartlara uygun, Mn ve Co konsantrasyonlarının yüksek olduğu tespit edilmiştir. Mn ve Fe konsantrasyonlarının yüksek çıktığı bölgelerde gerekli önlemlerin alınarak ölçümlerin düzenli olarak yapılması halk sağlığı açısından önem taşımaktadır.

Anahtar Kelimeler: Ağır Metal, Bingöl, Su

\section{Giriş}

Dünyamızın 3’4’ü sularla kaplıdır. Yaşamsal aktivitelerin düzenli devam edebilmesi için organizmanın belli bir miktar su bulundurması ve organizma içersinde bunu belli bir denge içinde tutması gerekmektedir. Organizmadaki suyun herhangi bir sebeple azalması önemli sağlık sorunları oluşturabilmektedir. (Yalçın, 2005)

Dünyada bulunmakta olan suyun \% 97,6'sı denizler ve okyanuslarda tuzlu su şeklinde bulunmaktadır. Kutup bölgelerinde ve buzullar şeklinde olan su ise dünyada bulunan suyun \% 1,9'unu oluşturmaktadır. $\mathrm{Bu}$ bilgilere göre, insanoğlunun yararlanabileceği su dünyada bulunan toplam suyu miktarının yalnızca \% 0,5'ini teşkil etmektedir. Yüzeydeki su, toprak altına geçerken toprak tarafından filtre edilir ve içerisindeki asılı maddeler, bakteri ve diğer mikroorganizmalar kısmen yada tamamen temizlenir; ancak bu olay sırasında toprakta bulunan madensel tuzlar da suya geçer. Bu sebeple yeraltı sularında yüzeydeki sulara oranla daha fazla miktarda mineral bulunmaktadır. Suya geçen bu minerallerin bazılarının belli miktarda su içerisinde olması istenen bir olaydır. Kalsiyum ve flor buna örnek verilebilir. Fakat toksik etki gösteren maddelerden hiçbirinin suda bulunması istenmemektedir (Güler, 1997).

Kimyasal kirlilik olarak değerlendirilen diğer bir kirlilik de Ağır metal kirliliğidir. Kimyasal kirliliğe yol açan kirleticilere deterjanlar, boyalar, petrol ürünleri, ve pestisitler örnek olarak gösterilebilir. Başlıca ağır metaller $\mathrm{Zn}, \mathrm{Cu}, \mathrm{Pb}, \mathrm{Fe}, \mathrm{Co}, \mathrm{Hg}, \mathrm{Mn}$, Se, Cr, V, Cd ve Ni'dir. Bu metallerin pek çoğu canlı yaşamı için elzemdir ve organizmada organik moleküllerin ve proteinlerin yapılarında kullanılmaktadır. (Hafızoğlu ve Tekin, 2004). Ağır metaller karıştığı sular ile birlikte taşınarak denizdeki canlılara oradan toprağa ve topraktan da insanlara kadar ulaşabilmektedir (Aközcan, 2009).

1- $\quad$ Bakır birçok şekilde bulunabilir, örneğin; içme suyu, hava ve yiyeceklerde. Ev tesisat sistemlerinde kullanan bakır borular sebebiyle insanlar, borulardan suya karışan bakırın fazla miktarlarına maruz kalabilmektedirler. Bu şekilde uzun süreli etkilenme ağız, burun ve gözlerde tahrişe sebep olabilmekte ve mide ağrısı, baş ağrısı, kusma, baş dönmesi ve ishale sebep olabilmektedir. Beyin hasarı, karaciğer sirozu, böbrek hastalığı ve bakır birikimi ile oluşabilen Wilson Hastalığı, kronik bakır zehirlenmesi ile ortaya çıkan rahatsılıklardandır (URL-1, 2019).

2- $\quad$ Mangan insan vücudunda başlıca bağ ve kemik doku oluşumu, üreme ve büyüme fonksiyonları, lipid ve karbonhidrat metabolizmalarıyla bağlantılı metalloenzimlerin komponenti ve enzim aktivatörü şeklinde de görev görmektedir (Belce 2002). Fazla miktarda mangan ihtiva eden bazı gıdalar pirinç, tahıllar, yumurta, yeşil fasulye, soya fasulyesi, zeytinyağı, fındık ve istiridyedir. Manganın çok yüksek miktarda birikimi insan vücudunda toksik etki göstermektedir (Şanlı 2002).

İnsan sağlığı için elzem olan Vitamin B B'nin yapısında kobalt bulunmaktadır. Fakat yinede bu elementin fazlası insan sağlığını etkileyebilmektedir. Havadan soluk alma ile vücuda giren kobaltın yüksek miktarları zatürre ve astım gibi akciğer hastalıklarına sebep olabilmektedir. (URL-2, 2019).

Dokulara oksijen taşınması ve hücresel oksidatif mekanizmalar gibi hayatsal önem taşıyan pek çok olayın içerisinde demir bulunmaktadır. Birçok enzimin yapısında kofaktör olarak bulunmaktadır (Belce 2002). Demir mide bağırsak kanalında hasara sebep olarak organizmanın ihtiyacından fazla demir alımasına neden olup toksik etkiye yol açabilir (Kaya ve Akar 1998). 
Tablo 1. TS- 266 içme ve kullanım suyu standartları (URL-3, 2019)

\begin{tabular}{|c|c|c|c|}
\hline \multicolumn{4}{|c|}{ TS - 266 STANDARTLARI } \\
\hline \multicolumn{4}{|c|}{ FİZİKOKİMYASAL ÖZELLİKLER } \\
\hline PARAMETRE & BİRİM & $\begin{array}{c}\text { İÇME VE } \\
\text { KULLANMA } \\
\text { SULARI }\end{array}$ & $\begin{array}{l}\text { KAYNAK } \\
\text { SULARI }\end{array}$ \\
\hline BULANIKLIK & Birim & 5 & 5 \\
\hline RENK & $\mathrm{Pt}-\mathrm{Co}$ & $1-20$ & 1 \\
\hline $\begin{array}{l}\text { TOPLAM } \\
\text { DEMIR }\end{array}$ & $\mathrm{mg} / \mathrm{lt}$ & $0,05-0,2$ & 0,05 \\
\hline AMONYUM & $\mathrm{mg} / \mathrm{lt}$ & $0,05-0,5$ & 0,05 \\
\hline NITTRIT & $\mathrm{mg} / \mathrm{lt}$ & $0,1-0,5$ & 0,1 \\
\hline KLORÜR & $\mathrm{mg} / \mathrm{lt}$ & $30-250$ & 30 \\
\hline $\mathrm{PH}$ & - & $6,5-9,5$ & $6,5-9,5$ \\
\hline İLETKENLİK & $\mathrm{ms} / \mathrm{cm}$ & $650-2500$ & 650 \\
\hline \multicolumn{4}{|c|}{$\begin{array}{l}\text { SUDA FAZLA MIKTARDA BULUNMASI ISTENMEYEN } \\
\text { MADDELER }\end{array}$} \\
\hline PARAMETRE & BİRİM & $\begin{array}{c}\text { İÇME VE } \\
\text { KULLANMA } \\
\text { SULARI }\end{array}$ & $\begin{array}{l}\text { KAYNAK } \\
\text { SULARI }\end{array}$ \\
\hline NITRAT & $\mathrm{mg} / \mathrm{lt}$ & $25-50$ & 25 \\
\hline SÜLFAT & $\mathrm{mg} / \mathrm{lt}$ & $25-250$ & 25 \\
\hline SODYUM & $\mathrm{mg} / \mathrm{lt}$ & $100-200$ & 100 \\
\hline ALÜMINYUM & $\mathrm{mg} / \mathrm{lt}$ & $0-0,2$ & 0,2 \\
\hline BOR & $\mathrm{mg} / \mathrm{lt}$ & $0-0,001$ & 0,001 \\
\hline MANGAN & $\mathrm{mg} / \mathrm{lt}$ & $0,02-0,05$ & 0,02 \\
\hline BAKIR & $\mathrm{mg} / \mathrm{lt}$ & $0,1-2$ & 0,1 \\
\hline FLORÜR & $\mathrm{mg} / \mathrm{lt}$ & $1-1,5$ & 1 \\
\hline ARSENİK & $\mathrm{mg} / \mathrm{lt}$ & $0-0,01$ & 0,01 \\
\hline KADMIYYUM & $\mathrm{mg} / \mathrm{lt}$ & $0-0,005$ & 0,005 \\
\hline SİYANÜR & $\mathrm{mg} / \mathrm{lt}$ & $0-0,05$ & 0,05 \\
\hline KROM & $\mathrm{mg} / \mathrm{lt}$ & $0-0,05$ & 0,05 \\
\hline CIVA & $\mathrm{mg} / \mathrm{lt}$ & $0-0,001$ & 0,001 \\
\hline NİKEL & $\mathrm{mg} / \mathrm{lt}$ & $0-0,02$ & 0,02 \\
\hline KURŞUN & $\mathrm{mg} / \mathrm{lt}$ & $0-0,01$ & 0,01 \\
\hline
\end{tabular}


Tablo 2. Bazı toksik ağır metal parametreleri (Su Kirliliği Kontrol Yönetmeliği) (URL-3, 2019)

\begin{tabular}{|l|l|c|c|c|c|}
\hline \multirow{2}{*}{} & \multirow{2}{*}{ Su Kalite Parametreleri } & \multicolumn{4}{|c|}{ Su Kalite Sinıfları (TSE) } \\
\cline { 3 - 6 } & & I & II & III & IV \\
\hline 1 & Çinko $(\mathrm{Zn})$ & 200 & 500 & 2000 & $>2000$ \\
\hline 2 & Kurşun $(\mathrm{Pb})$ & 10 & 20 & 50 & $>50$ \\
\hline 3 & Kadmiyum $(\mathrm{Cd})$ & 3 & 5 & 10 & $>10$ \\
\hline 4 & Krom $(\mathrm{Cr})$ & 20 & 50 & 200 & $>200$ \\
\hline 5 & Nikel $(\mathrm{Ni})$ & 20 & 50 & 200 & $>200$ \\
\hline 6 & Bakır $(\mathrm{Cu})$ & 20 & 50 & 200 & $>200$ \\
\hline 7 & Kobalt $(\mathrm{Co})$ & 10 & 20 & 200 & $>200$ \\
\hline 8 & Mangan $(\mathrm{Mn})$ & 100 & 500 & 3000 & $>3000$ \\
\hline
\end{tabular}

Ülkemizde TS 266 ile belirlenen İçme ve kullanma suları için toksik madde limitleri Tablo 1 de verilmiştir. Ülkeler ulusal içme, kaynak suyu ve kullanma suyu standartlarını kendileri belirlemektedirler. Ülkemizde TS-266 da belirlenen standartlar kullanılmaktadır (Kahraman, 2007). Bu çalışma Türkiye'nin Bingöl il merkezi ve ilçelerinde içme suyu örneklerinde bulunan ağır metal $(\mathrm{Cu}, \mathrm{Mn}, \mathrm{Co}, \mathrm{Fe})$ düzeylerini araştırmak amacıyla planlanmıştır.

\section{Materyal ve Metod}

Çalışma materyalini oluşturan su numuneleri, Türkiye'nin Bingöl il merkezi ve ona bağlı 7 ilçeden içme suyu sağlayıcılarından toplam 13 adet temin edilmiştir. Bazı ilçeler içme suyunu tek bir kaynaktan karşılarken bazıları birden fazla kaynaktan karşılamaktadır. Toplanan numuneler yerleşim yerlerinin içme suyu ihtiyacını karşılayan su kaynaklarından temin edilmiştir. Araziden toplanan su numuneleri öncesinde hazırlanmış seyreltik $\mathrm{HNO}_{3}$ çözeltisi ile yıkanıp kurutulmuş $1500 \mathrm{ml}$ hacimli PET şişelerle alınmıştır. Alınan su örneklerinin üzerine kaynakta $15 \mathrm{ml} \% 65^{\prime}$ lik $\mathrm{HNO}_{3}$ çözeltisinden ilave edilmiştir. Böylece ortamın asidik olması sağlanarak toplanan su örneklerinde bulunan mikroorganizmaların canlılıklarına son verilmiş ve ortamdaki metallerin farklı formlar haline geçmelerinin önüne geçilmiştir. Toplanan su numuneleri analiz zamanına kadar soğutucu içersinde dondurularak saklanmıştır.

Su numunelerinin metal analizleri Bingöl Üniversitesi Merkez Laboratuvarında bulunan Perkin Elmer AAS800 Atomik Absorbsiyon Spektrofotometresi cihazı ile yapılmıştır. Analize başlamadan her metal için 1 ppm, 0.1 ppm 0.01 ppm ve 0.001 ppm konsantrasyonlarında standart çözeltileri hazırlanmıştır. Bu standart çözeltiler AAS cihazında okutularak cihazın kendi standart grafiklerini çizmesi sağlanmıştır. Elde edilen grafikler yardımı ile analizler gerçekleştirilmiştir (URL-4, 2019).

\section{Bulgular}

Alınan su numunelerinde analizi gerçekleştirilen metallerden; Bakır'ın ortalama değeri 0,306 $\pm 0,08$ ppm olarak tespit edilmiştir. 13 numunenin 6'sında kaydedilen değerler ortalama değerin altında, kalan 7 numuneden elde edilen verilerin ise ortalama değerin üzerinde olduğu tespit edilmiştir. Mangan'ın ortalama değeri $0,163 \pm 0,05$ ppm olarak tespit edilmiştir. 13 numunenin 6'sında kaydedilen değerler ortalama değerin altında, kalan 7 numuneden elde edilen verilerin ise ortalama değerin üzerinde olduğu tespit edilmiştir. Kobalt' 1 ortalama değeri 0,042 $\pm 0,01$ ppm olarak tespit edilmiştir. 13 numunenin 6'sında kaydedilen değerler ortalama değerin altında, kalan 7 numuneden elde edilen verilerin ise ortalama değerin üzerinde olduğu tespit edilmiştir. Demir'in ortalama değeri 0,074 \pm 0,02 ppm olarak tespit edilmiştir. 13 numunenin 4'ünde kaydedilen değerler ortalama değerin altında, kalan 9 numuneden elde edilen verilerin ise ortalama değerin üzerinde olduğu tespit edilmiştir. Elde edilen veriler Tablo 3 ’te verilmiştir. 
Tablo 3 Türkiye'nin Bingöl yöresindeki 13 farklı noktadan alınan içme sularındaki metal derişimleri (ppm)

\begin{tabular}{|l|c|c|c|c|}
\hline $\begin{array}{l}\text { Su örneği alınan } \\
\text { yerler }\end{array}$ & Bakır (Cu) & $\begin{array}{c}\text { Mangan } \\
(\mathbf{M n})\end{array}$ & Kobalt (Co) & Demir (Fe) \\
\hline Bingöl Merkez 1 & 0.338 & 0.123 & 0.057 & 0.068 \\
\hline Bingöl Merkez 2 & 0.284 & 0.224 & 0.072 & 0.059 \\
\hline Bingöl Merkez 3 & 0.283 & 0.138 & 0.023 & 0.075 \\
\hline Bingö1 Merkez 4 & 0.320 & 0.070 & 0.072 & 0.077 \\
\hline Kiğ1 1 & 0.270 & 0.118 & 0.047 & 0.082 \\
\hline Kiğ1 2 & 0.261 & 0.178 & 0.025 & 0.081 \\
\hline Yedisu & 0.337 & 0.095 & 0.101 & 0.072 \\
\hline Karlıva 1 & 0.335 & 0.218 & 0.061 & 0.057 \\
\hline Karlıva 2 & 0.309 & 0.219 & 0.008 & 0.075 \\
\hline Solhan & 0.333 & 0.188 & 0.043 & 0.085 \\
\hline Adaklı & 0.301 & 0.207 & 0.009 & 0.088 \\
\hline Genç & 0.306 & 0.192 & 0.007 & 0.068 \\
\hline Yayladere & 0.296 & 0.154 & 0.017 & 0.080 \\
\hline Ortalama Değer \pm SEM & $0.306 \pm 0.08$ & $0.163 \pm 0.05$ & $0.042 \pm 0.01$ & $0.074 \pm 0.02$ \\
\hline
\end{tabular}

\section{Tartışma ve sonuç}

Bu çalışmada Türkiye'nin Bingöl il merkezi ve ilçelerinde bulunan 13 farklı noktadan yaz mevsiminde içme suyu kaynaklarından alınan su numunelerinde bu çalışma için belirlenen ağır metallerin $(\mathrm{Cu}, \mathrm{Mn}$, $\mathrm{Co}, \mathrm{Fe})$ konsantrasyonları tespit edildi.

Sularda bulunabilecek ağır metallerin tespiti insan vücudu ve sağlığına verebileceği zararlar açısından önem arzetmektedir. Bu sebeple Avrupa Birliği ve Dünya Sağlık Örgütü benzeri kuruluşlar sularda bulunabilecek ağır metaller için çeşitli standartlar ortaya koymuşlardır. Günümüzde Türkiye de kendi sınırları içeresindeki içme suları için standartlarını oluşturmuş (TS 266) ve insani tüketim amaçlı sularda bu standartları uygulamaktadır. Türkiye'nin Bingöl il merkezi ve ilçelerinde bulunan 13 farklı noktadan alınan su numunelerinde tespit edilen veriler değerlendirilerek şu sonuçlara ulaşılmıştır.

Araştırmamızda Bingöl il genelinde ortalama $\mathrm{Cu}$ konsantrasyonu 0.306 \pm 0.08 ppm olarak ölçülmüştür. Farklı noktalardan alınan su numunelerinden 6.sı olan Kiğı mevkiinden alınan Kiğ 2 numunesi 0.261 ppm lik $\mathrm{Cu}$ konsantrasyonu ile en düşük, 1.numune olan Bingöl Merkez 1 numunesinde ise $0.338 \mathrm{ppm} \mathrm{lik} \mathrm{Cu}$ konsantrasyonu ile en yüksek $\mathrm{Cu}$ konsantrasyonuna sahiptir. $\mathrm{Cu}$ konsantrasyonu tüm bölgelerde maksimum değerin altında ölçülmüştür. Konya ilinde yapılan çalışmalarda kuyu ve şebeke suyu $\mathrm{Cu}$ konsantrasyonu analizlerinde elde edilen sonuçların standart değerlerin altında olduğu görülmüştür (Yalçın, 2005; Kahraman, 2007). Çanakkale ilinde içme sularında yapılan ağır metal analizlerinde $\mathrm{Cu}$ konsantrasyonlarının standart değerlerin altında olduğunu tespit edilmiştir (Kovancı, 2008). Van, ilinde yapılan bir çalışmada ölçülen $\mathrm{Cu}$ konsantrasyonlarının standart değerleri aşmadığı bildirilmiştir (Alemdar ve ark.,2007). Yaşar ve arkadaşları (2016), Mardin ilinde yaptıkları çalışmada bakır değerlerini ortalama 0.023 ppm düzeyinde ölçmüşlerdir. Dicle nehri suyunda yapılan bir çalışmada bakır düzeyleri yaz aylarında numune alınan 3 farklı bölgede sırasıyla $0.092,0.058$ ve $0.075 \mathrm{mg} / 1$ düzeylerinde ölçülmüştür (Karadede-Akin ve Ünlü, 2007). Organizma içersinde iskelet mineralizasyonu, bağ doku sentezi, bağışıklık sistemi, hemoglobin sentezi ve kolesterol metabolizmasında önemli görevleri bulunmaktadır (Saldamlı ve Uygun, 1998).

Çalışmamızda Mn için yapılan analizler sonucunda 13 numuneden elde edilen ortalama değer $0.163 \pm 0,05$ 
ppm olarak ölçülmüştür. Bu değerin TS.266 standartlarına göre yüksek olduğu görülmüştür. Alınan su numunelerinden 5.si olan Kiğ 11 numunesi 0,118 ppm lik değeri ile en düşük değere sahipken 2. numune olan Bingöl Merkez 2 suyu en yüksek değer olan 0,224 ppm değeri ile standartlara göre en uygun olmayan su numunesi olmuştur. Mn miktarları tüm numunelerde standart değerlerin üzerinde çıkmıştır. Konya ilinde yapılan bir çalışmada Mn konsantrasyonları kuyu sularında belirlenen standartların üzerinde bulunmuştur bunun sebebi olarak da jeolojik yapı ve organize sanayi bölgesinden su içerisine mangan karışmış olabileceği söylenmiştir (Kahraman, 2007). Aynı bölgedeki farklı bir çalışmada ise içme sularında Mn konsantrasyonlarının standart değerlerin altında çıktığı tespit edilmiştir (Yalçın, 2005). Manisa ilinde Gediz nehrinden alınan su numunelerinde yapılan ölçümlerinde Mn konsantrasyonlarının standart değerlerin üzerinde çıktığı bildirilmiştir (Aksoy, 2005). Van ilinde yapılan bir araştırmada Mn düzeylerinin standart değerlerin üzerinde bulunduğu bildirilmiştir (Alemdar ve ark., 2007). Mardin ilinde yapılan bir çalışmada tüm numunelerin Mn düzeylerinin standartların üzerinde olduğu tespit edilmiştir (Yaşar ve ark., 2016).

Yaptığımız çalışmada Co için yapılan analizler sonucunda numunelerde ölçülen ortalama değer $0,042 \pm 0,01$ ppm olarak bulunmuştur. Su numunelerinden 12.si olan Genç ilçesi numunesinde 0,007 ppm ile Co açısından en düşük değer, 7. numune olan Yedisu ilçe suyunda ise 0,101 ppm ile en yüksek değer tespit edilmiştir. Manisa ilinde yapılan bir çalışmada Gediz nehri su örneklerinde Co konsantrasyonu ölçümleri yapılmış sonuçlar su kalite standartlarına göre III. kalite su olarak değerlendirilmiştir (Aksoy, 2005). Mardin ilinde içme sularında yapılan başka bir çalışmada numunelerdeki Co konsantrasyonunun 3 numunede su kalite standartlarına göre II. kalite kalan numunelerde ise III. kalite su tanımına uyduğu bildirilmiştir (Yaşar ve ark., 2016). Van ilinde yapılan bir çalışmada ise kuyu ve içme sularında tespit edilen Co konsantrasyonlarına göre suların III. kalite sular sınıfında yer aldığı bildirilmiştir (Alemdar ve ark., 2007). Kobalt vücutta tiroid hormonlarının sentezi ve demir kullanımında önemli bir yapıdır. Genellikle kirliliği endüstriyel atık kaynaklıdır. Fazla miktarlarda alınması toksik etki gösterir (Munsuz ve Ünver, 1995; Saldamlı ve Uygun, 1998).

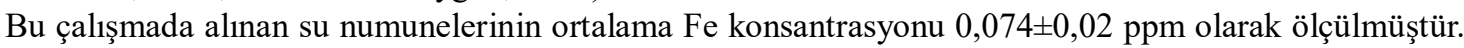
İl genelinde su numunelerinden 8.si olan ve Karlıova 1 su numunesinde Fe açısından 0,057 ppm ile en düşük değer, 11. numune olan Adaklı numunesinde ise 0,088 ppm lik değerle en yüksek değer tespit edilmiştir. Ölçüm sonuçlarına göre Bingöl ilinde hiçbir bölgede Fe konsantrasyonu TSE standartlarının üzerinde çıkmamaktadır. Konya ili içme sularında (Yalçın, 2005) ve Van ili içme ve kuyu sularında (Alemdar ve ark., 2007) yapılan Fe konsantrasyonları ölçümleri sonucu çıkan değerlerin TSE standartlara uygun olduğu bildirilmiştir. Demir, hemoglobin ve miyoglobin gibi vücutta oksijen taşımada görevli kromoproteinlerin, ksantin oksidaz, sitokrom oksidaz, ve katalaz gibi bazı enzimlerin yapısında bulunur. (Belce 2002).

Çalışmamızda elde ettiğimiz verilere dayanarak; tüm numunelerin $\mathrm{Cu}$ konsantrasyonu bakımından standart değerler içerisinde olduğu görülmüştür, Özellikle Mangan ve Kobalt metalleri bakımından Bingöl il genelinde bulunan içme sularının zengin olduğu görülmüş, kobalt için TSE'nin bir standart değeri vermemesine karşın elde edilen sonuçların yüksek olduğu düşünülmektedir. Bunun sebebi bölgenin jeolojik yapısından kaynaklanabilir. Bu durum çeşitli sağlık sorunlarına sebebiyet verebilir, bu durumun çözülebilmesi için yerel yöneticilerin gerekli önlemleri alması gerektiği düşünülmektedir. Fe konsantrasyonu bakımından tüm numunelerin verilerinin standart değerler arasında olduğu saptanmıştır. Çoğunlukla fazla gelişmemiş şehirler ve ilçelerinde yerel yönetimlerin sağlıklı kullanma ve içme suyu alt yapıları oluşturamadıkları görülmektedir. Bu sağlıksız alt yapıların da kullanma ve içme sularında çeşitli sorunlara sebep olduğu görülmektedir. Bu sebeple uzun zaman bakımı yapılmayan ve eskimiş borular kaynaklı metal kirliliğinin bölge halkının sağlıklı ve standartlara uygun kullanma ve içme suyunu temin etmelerini güçleştirdiği görülmektedir. İnsan sağlı̆̆ açısından sıkıntıların yaşanmaması için konu ile ilgili yetkililere büyük sorumluluklar düşmektedir.

\section{Kaynaklar}

Aközcan, S. (2009): Didim ve İzmir körfezi sediment, deniz suyu ve farklı deniz organizmalarında bazı radyonüklid ve ağır metal düzeylerinin izlenmesi. Ege Üniversitesi Fen Bilimleri Enstitüsü, İzmir. 
Aksoy, G., (2005). Gediz nehri ağzında su, sediment ve planktondaki ağır metal düzeylerinin ölçülmesi. Celal Bayar Üniversitesi Fen Bilimleri Enstitüsü Hidrobiyoloji Yüksek Lisans Programı, Yüksek lisans tezi, Manisa.

Alemdar, S., Ağaoğlu, S., Alişarlı, M. \& Dede, S. (2007). Van bölgesi su kaynaklarında ağır metal kirlilik düzeyleri. Vet. Bil. Derg., 23, 1, 19-29,

Belce, A. (2002) Mineraller, in "Insan Biyokimyası" Ed. by Onat T, Emerk K ve Sözmen EY, 529 537, Palme Yayıncılık, Ankara.

Güler, Ç. (1997). Su kalitesi, Çevre Sağlı̆̆1 Kaynakları Dizisi (43), Ankara.

Hafızoğlu, E. \& Tekin, F. (2004): Gediz Nehrinde (Manisa) Ağır Metal Kirliliğinin İncelenmesi. Soma Meslek Yüksekokulu Teknik Bilimler Dergisi, 2(2), 41-51.

Kahraman, Ü.C. (2007). Konya garnizon birliklerindeki kuyu suları ile şehir şebeke sularının su kalitesi ve ağır metaller yönünden karşılaştırılması. Selçuk Üniversitesi Sağlık Bilimleri Enstitüsü Besin Hijyeni ve Teknolojisi Anabilim Dalı, Yüksek Lisans Tezi, Konya.

Karadede-Akin, H, \& Ünlü, E, (2007). Heavy Metal Concentrations in Water, Sediment, Fish and Some Benthic Organisms from Tigris River, Turkey. Environ Monit Assess, 131:323-337

Kaya, S. \& Akar, F. (1998). Metaller in "Veteriner Hekimliğinde Toksikoloji" Ed. by Kaya S, Pirinçci İ ve Bilgili A, 119 -143, 1.Bask1, Medisan Yayınc1lık, Ankara.

Kovancı, A. (2008). Çanakkale şehir şebeke suyunda ağır metal analizi ve bakteriyolojik inceleme. Çanakkale Onsekiz Mart Üniversitesi Fen Bilimleri Enstitüsü Biyoloji Anabilim Dalı, Yüksek Lisans Tezi, Çanakkale.

Munsuz, N. \& Ünver, İ. (1995) Su Kalitesi. Ankara Üniversitesi. Ziraat Fak. Yayın No: 1389, Ders Kitab1, Ankara.

Saldamlı, İ. \& Uygun, Ü. (1998). Gıda Katkı Maddeleri, Saldamlı İ (ed) Gıda Kimyası, Hacettepe Üniversitesi Yayınları, Ankara.

Şanlı, Y. (2002). Veteriner Klinik Toksikoloji, Mesipres Yayıncılık, 2. Baskı, p,744 -751, Ankara.

URL-1, (2012) Water Treatment Solutions ( $\mathrm{Su}$ Arıtma Çözümleri) web sitesi http://www.lenntech.com/periodic/elements/cu.htm (20 Ocak 2019)

URL-2, (2019) Water Treatment Solutions ( $\mathrm{Su}$ Arıtma Çözümleri) web sitesi http://www.lenntech.com/periodic/elements/co.htm (20 Ocak 2019)

URL-3, (2019). TS-266 İçme Kullanım Suyu Standartları. http://www.teknikaritma.com.tr/tr/iss.asp (20 Ocak 2019)

URL-4, (2019). Standart methods for the Examination Water and Wastewater, https://www.mwa.co.th/download/file_upload/SMWW_1000-3000.pdf(20 Ocak 2019)

Yalçın, M. (2005). Konya bölgesi içme sularındaki ağır metal düzeylerinin araştırılması, Selçuk Üniversitesi Sağlık Bilimleri Enstitüsü, Yüksek Lisans Tezi, Konya

Yaşar, S., Üstek, M.A., Bengü, A.Ş. \& Mis, L. (2016). Mardin bölgesi içme sularında ağır metal düzeylerinin araştırılması. Cumhuriyet Üniv. Săg. Bil. Enst. Derg., (1)2, 63-71 